\title{
Modern Arctic Climate Research: Progress, Change of Concepts, and Urgent Problems
}

\author{
V. A. Semenov ${ }^{a, b}, *$ \\ ${ }^{a}$ Obukhov Institute of Atmospheric Physics, Russian Academy of Sciences, Moscow, 119017 Russia \\ ${ }^{b}$ Institute of Geography, Russian Academy of Sciences, Moscow, 119017 Russia \\ *e-mail: vasemenov@ifaran.ru \\ Received September 22, 2020; revised October 8, 2020; accepted October 14, 2020
}

\begin{abstract}
A review of some major advances in studies of Arctic climate change in the last decade is presented. Mechanisms of positive feedbacks leading to accelerated climate changes in the northern high latitudes are considered. Some recently popular hypotheses of the rapid Arctic climate change that failed when confronted with observed climate changes are exemplified. Urgent problems regarding Arctic climate change are formulated.
\end{abstract}

Keywords: Arctic climate change, feedbacks in the climate system, natural climate variability

DOI: $10.1134 /$ S0001433821010114

\section{INTRODUCTION}

Arctic climate changes during the recent decades are probably the most spectacular regional manifestation of the ongoing global warming. The rates of temperature rise in the Arctic since the late 1970s have been roughly 2.5 times as large as those globally averaged (Fig. 1). The September sea-ice area in the Arctic has reduced by about $40 \%$ over the last 40 years [1]. Paleoreconstruction records indicate that the current Arctic warming has been unprecedented over the past 400 years at least [2], and the reduction in sea-ice exceeds all the negative anomalies in the last millennium [3]. Such a rapid warming in the Arctic significantly decreases the meridional temperature gradient in the Northern Hemisphere (NH) mid- and high latitudes and alters the strength and position of heat sources and sinks at the lower boundary of the atmosphere (in particular, due to sea-ice loss). These changes, in turn, are accompanied by circulation change; shifts in weather regimes; and more frequent extreme weather events, including those in the northern Eurasian and North American regions [4, 5]. The Arctic climate change has been studied in a large number of works, which are reviewed in assessment reports of the Intergovernmental Panel on Climate Change (https://www.ipcc.ch/), in the Arctic Climate Impact Assessment Overview report [6], and in the Russian Federal Service for Hydrometeorology and Environmental Monitoring (Roshydromet) assessment climate reports [7] with special sections focusing on Arctic climate change. The past two decades have shown an increase in the number and quality of satellite observations; improvements in remote-sensing data-processing procedures; the accumulation of new oceanographic data; considerable progress in numerical simulation of the atmosphere, ocean, climate, and Earth climate system as a whole; and the creation of new atmospheric and oceanic reanalyses. With increased computational capabilities, this has provided a much more accurate and complete simulation and diagnosis of the Arctic climatic processes. All this has favored not only progress in understanding mechanisms of climate changes occurring during recent years, but, in some regions, also a qualitative change of knowledge about processes and mechanisms of climate dynamics in the Arctic, both at present and in the past.

This paper presents a review of some important, from the author's point of view, recent advances in Arctic climate research, gives examples of how the concepts critical to understanding climate dynamics have changed, and suggests problems that remain to be solved. For reasons of limited space and breadth of the topic, the review is not meant to be comprehensive, but rather offers the author's subjective view, largely based on personal experience and the results of Arctic climate research in the past two decades.

\section{FEATURES OF TEMPERATURE AND SEA-ICE AREA CHANGES IN THE ARCTIC}

The major features of the Arctic climate change can be deduced by comparing the dynamics of global and Arctic temperature during the instrumental observations period (Fig. 1). Much higher rates (more than doubled) of present warming in the Arctic relative to global warming since the 1970s are evident. This phe- 


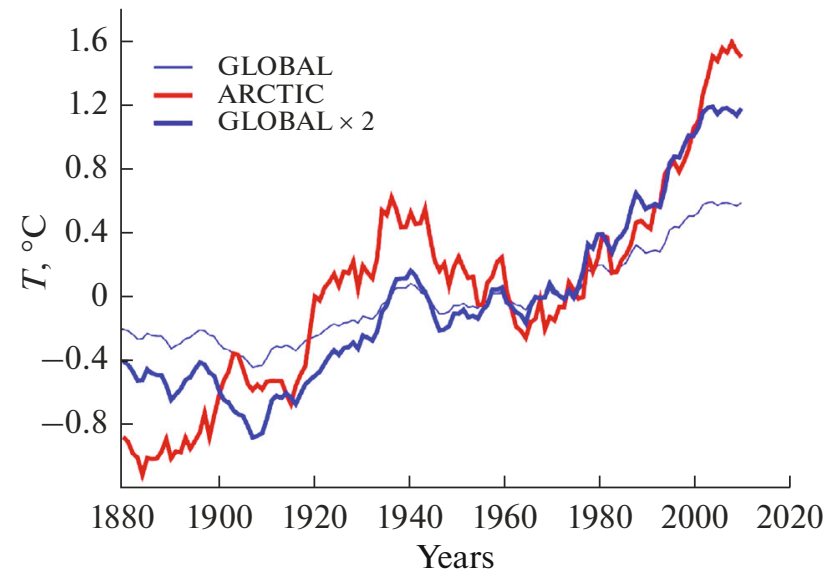

Fig. 1. Annual mean surface temperature anomalies $\left({ }^{\circ} \mathrm{C}\right)$ in the Arctic $\left(60^{\circ}-90^{\circ} \mathrm{N}\right.$, red curve), over the globe (thin blue curve), and doubled anomalies of global temperature (thick blue curve) from GISTEMP (13). Time series are smoothed with a 5-year running mean.

nomenon was called Arctic amplification (AA) [8]. Until recently, the main cause of AA was thought to be a positive surface temperature-albedo feedback, which is most pronounced in the presence of snow-ice cover in the NH high latitudes. Such a positive feedback was suggested by M. Budyko as the cause of climate instability in the energy balance model [9]. This hypothesis has begun to be revised since the early 2000s [10]. A recent study [11] has suggested that AA occurs in idealized experiments for an aquaplanet with no positive surface albedo feedback. The increase in the meridional heat transport to high latitudes due to increased latent heat flux played an important role in AA in these experiments. A quantitative analysis of the various radiative and thermodynamic feedbacks in climate models with a stationary response to increasing greenhouse-gas concentrations has shown a significant (comparable in magnitude) contribution of three processes to the AA of global warming, which include changes in the height of the effective radiation emission height, positive albedo-temperature feedbacks, and the Planck effect [12].

The second specific feature of the Arctic climate change is a significant positive interdecadal temperature anomaly in the mid-20th century (Fig. 1), called the Early Twentieth Century Warming (ETCW). This global temperature anomaly is most pronounced in the NH high latitudes [14]. In the Arctic, the ETCW amplitude is well above (approximately twice) the global average (Fig. 1). While for global temperatures the present warming exceeded the ETCW peak in the latter half of the 1970s, it occurred in the Arctic only in the mid-1990s. Maximum temperatures at the Malye Karmakuly weather station (Novaya Zemlya) during the ETCW remained record-breaking until 2012 [15]. All this indicates larger internal climate variability in the Arctic, a regional enhancement of climate fluctu- ations in the NH high latitudes, or both. A persistent Arctic cooling after the ETCW, from the mid-1940s to the mid-1970s, made it impossible for a long time to speak of a significant tendency toward warming in the Arctic until the early 21 st century. One interesting example of such an uncertainty is J. Walsh's note of 1993 "The Elusive Arctic Warming" [16], where the negative Arctic temperature trend in the last (to that date) four decades was found from station and satellite observational data. It has also been suggested that such a tendency runs counter to the strongest greenhouseinduced Arctic warming projected by climate models.

The rates of temperature rise during the ETCW were comparable to current trends, globally and in the Arctic, although the rate of atmospheric greenhouse-gas concentration increase in the 1920s to the 1930s was approximately one-fourth of that in the last 40 years. Thus, anthropogenic emissions of greenhouse gases cannot explain the ETCW phenomenon. A hiatus in major volcanic eruptions and solar activity variations may have contributed to this warming [17], but they, according to model estimates, are unable either to explain such a rapid temperature rise in the mid-20th century.

Long-term (several-decade scale) natural fluctuations of climate are suggested to be an important factor in the ETCW. An obvious candidate for such fluctuations is the Atlantic Multidecadal Oscillation (AMO), quasi-periodic (with a period of 50-70 years) sea-surface temperature variations in the North Atlantic [18] thought to be associated with corresponding variations in the strength of Atlantic meridional overturning circulation (e.g., [19]). The AMO is in phase with Arctic temperature variations [20]. However, such variations explaining changes of meridional oceanic heat transport in the North Atlanitc across $30^{\circ} \mathrm{N}$, with amplitude of approximately $0.1 \mathrm{PW}$ (about $10 \%$ of the total oceanic heat transport), are linked rather weakly to variations of the heat transport across latitudes north of $65^{\circ} \mathrm{N}$ [21]. Although the hypothesis that the AMO is the main cause of quasi-cyclic fluctuations of the climate in the Arctic is most popular, there are some studies suggesting a role of other processes, which will be discussed below.

Thus, the ETCW is of interest not only as a significant climate anomaly in the historical past, but also as the key to understanding the current warming. If the internal climate variability is able to drive warming of such a magnitude, what is the contribution of natural variability to the current warming? This question remains open, and some model estimates indicate that such a contribution may be half of the observed warming during recent decades [20]. Under conditions of a strong long-term natural climate variability in the Arctic with a monotonic warming caused by global climate changes, the assessment of climate trends depends fundamentally (sometimes even qualitatively) on the length and start of the period chosen for analysis $[22,23]$. 
The third important feature of Arctic climate change follows from a comparison of the dynamics of Arctic temperature anomalies with dynamics of doubled anomalies of global temperature (Fig. 1). It can be seen that, with such scaling (given the AA effect) of the change, the doubled global temperature anomalies compare well with Arctic anomalies from 1960 through 2000, but anomalies during the ETCW are significantly different. There is also a difference between anomalies of the early 20th century. While global anomalies exhibit a hiatus in global warming, temperature in the Arctic continued to rise. This indicates the nonlinearity of the interaction of global warming and Arctic climate change and/or the independent dynamics of the Arctic system.

Thus, three important features of Arctic climate change, which imply major urgent scientific problems, are the AA of global climate change, significant internal (including multidecadal) climate variability and ETCW as its probable manifestation, and a nonlinear relationship between Arctic and global-average surface temperature changes.

\section{PROGRESS IN STUDIES OF ARCTIC PROCESSES}

As in other fields of physics, progress in climatechange research depends primarily on the appearance of new data on the dynamics of the Earth's climate system. In the Arctic, the problem with empirical data is particularly urgent because of severe weather conditions and the sea-ice cover that makes regular meteorological and oceanographic measurements difficult in many regions of the Arctic Ocean (AO).

Regular oceanographic measurements in the northern high latitudes, from the 1990s to the present, have provided a three-dimensional picture of Atlantic water inflow and transformation changes in the Arctic Basin over the past several decades. This has revealed important features of current changes and their mechanisms, including new assessments of the role that the oceanic inflow plays in sea-ice extent and thickness changes [24, 25]. Among major advances in experimental oceanography are direct (buoy-station) measurements of current velocity and water temperature (from the surface to the seafloor) in a section along the western entrance to the Barents Sea from 1997 [26], the annual Nansen and Amundsen Basins Observational System (NABOS) expeditions (since 2002) [24] aimed at exploring the transformation of Atlantic water in the Eurasian Basin of the Arctic, and the development of a Unified Database for Arctic and Subarctic Hydrography (UDASH) archive of temperature and salinity profiles for the $\mathrm{AO}$ and subpolar seas [27].

With a reduction in the amount of stationary meteorological observations in the Arctic after the collapse of the Soviet Union and the termination of the polar drifting station program in 1992, the number of satellites remotely sensing the atmosphere and surface of the Earth in the polar region has increased. One fundamentally important achievement here is the creation of Arctic sea-ice thickness data based on satellite altimetry. Unlike the sea-ice concentration determined quite precisely from satellite microwave radiometers since 1979 [28], the sea-ice thickness before the early 2000s was known only from miscellaneous and local data from stationary and submarine sonars; from measurements at drifting stations; and from aircraft data, including electromagnetic sensing and altimetry [29]. Empirical estimates of climatic trends in sea-ice thickness contained large uncertainties, from a decrease ranging from about $10 \%$ per decade in the last 40 years of the 20th century from submarine sonar data to $3 \%$ per decade according to measurements of ice-surface vibrations from Russian North Pole drifting stations [30, 31]. Estimates from simulations with ocean-sea ice general circulation models also differed significantly [32]. Satellite altimetry data of sufficient accuracy in 2003-2008 (NASA Ice, Cloud, and land Elevation Satellite (NASA ICESat)) and afterward from 2010 to the present (European Space Agency Cryosphere Satellite 2, ESA CryoSAT-2) have eventually allowed reliable estimates of sea-ice thickness and seasonal and interannual variations with almost the complete spatial coverage of the Arctic and with high spatial resolution [33]. Although the period of continuous records is only 10 years so far, the seasonal cycle and interannual fluctuations of sea-ice thickness are strongly suggestive of the reliability of oceanic reanalyses-ocean models using atmospheric reanalyses as boundary conditions and assimilating available data from oceanographic observations and sea-ice concentrations. Their results appeared to be very similar to satellite data $[34,35]$.

The development of oceanic reanalyses in the early 20 th century is a substantial progress in the Arctic climate research. The reanalyses provide full spatial and temporal datasets of sea-ice characteristics, temperature, salinity, current velocity, and ocean surface height, making it possible to investigate processes in regions and at depths where measurements have never been made. Results from the Pan-Arctic Ice Ocean Modeling and Assimilation System (PIOMAS) reanalysis [34], providing data since 1979, are available for the analysis of Arctic sea-ice characteristics. High-resolution (1/4 deg) MERCATOR reanalysis [35] provides data on ocean characteristics for the period from 1993. Changes in the mean sea-ice thickness in the Arctic from these two reanalyses are shown in Fig. 2a. It can be seen that the sea-ice thickness in a minimum of the seasonal cycle has decreased nearly by half since 1980. There are also significant interannual variations, particularly a large increase from 2010 to 2015, which occurred during just the first years of the CryoSAT-2 mission [36]. 

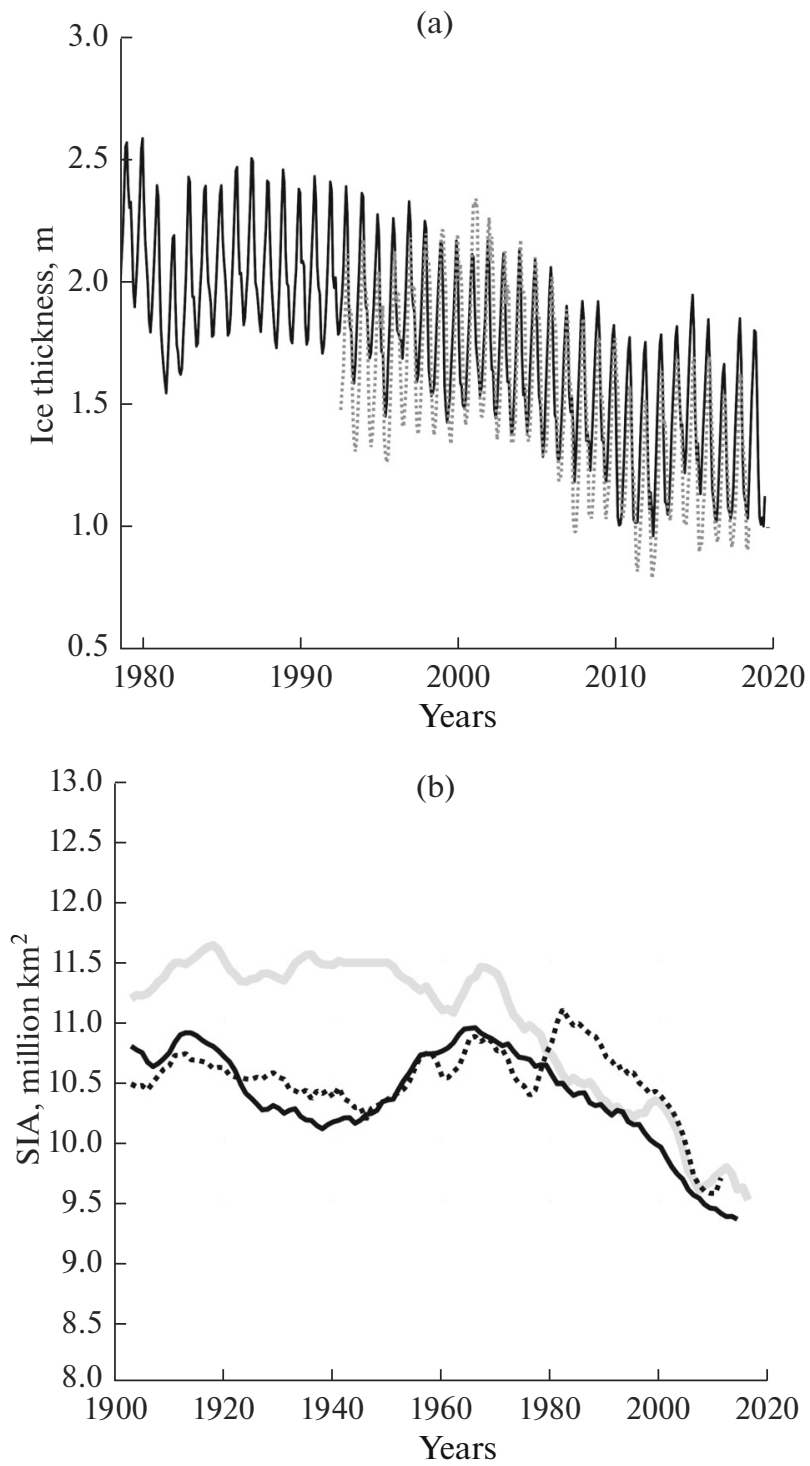

Fig. 2. (a) Monthly mean sea-ice thickness (m) in the Arctic from PIOMAS (solid curve) and Mercator (dashed curve); (b) annual mean sea-ice thickness in the Arctic from HadISST1 (thick grey curve), SIBT1850 (dashed curve), and gridded data reconstructed using covariance analysis from temperature data (solid curve) [37]. Time series are smoothed with a 7-year running mean.

In atmospheric reanalyses for the Arctic, the lack of regular atmospheric radiosonde data in ice-covered areas and sparse station observations in pan-Arctic regions lead to large biases [38]. They are associated primarily with incorrectly represented cloud cover, surface inversions, and turbulent heat fluxes over ice. Assimilating satellite data in the nearest future can hardly improve the situation because of, apart from other problems, data inhomogeneity and uncertainty in the solution of the inverse problem of atmospheric temperature and humidity retrieval using GPS. The problem of reanalysis error decrease should be solved by improving parameterizations of the abovementioned processes in atmospheric models and assimilating more data from direct observations.

At the same time, there has been progress in creating reanalyses with temporal data coverage not only for the era of regular aerological and satellite observations, but also for the entire 20th century. Three 20th-century reanalyses developed in the early 21 st century include the National Oceanic and Atmospheric Administration-Cooperative Institute for Research in Environmental Sciences (NOAA-CIRES) Twentieth-Century Reanalysis V2 [39], the European Centre for MediumRange Weather Forecasts (ECMWF) interim Reanalysis of the twentieth century (ERA20C) [40], and the ECMWF Coupled Ocean-Atmosphere Reanalysis of the twentieth century (CERA20C) [41]. Even though such reanalyses providing data for all basic atmospheric parameters with full spatial and temporal coverage are attractive, they should be used with caution for the Arctic climate change analysis before the 1950s because of an incorrect temperature representation [14].

A recent reanalysis of Arctic sea-ice characteristics for the entire 20th century should also be mentioned, PIOMAS-20C [42]. Note that PIOMAS-20C uses ERA20C data as boundary conditions for the ocean model and, hence, retranslates biases in reproducing atmospheric parameters for the first half of the 20th century, which are inherent in ERA20C.

In addition to new observational data for the current period, the time range of knowledge about key parameters of the Arctic climate system is being extended in recent years to the past, both historical and on millennial scales. Sea-ice data are a striking example. In the non-Russian science literature, the evolution of the total sea-ice area in the Arctic before the beginning of a reduction in sea ice in the 1970s was, until recently, widely thought to be a plateau with no significant decadal or multidecadal variations (Fig. 2b, HadISST1). Although data on the sea-ice cover of the eastern Arctic from the Arctic and Antarctic Research Institute (AARI) demonstrated a significant negative summer anomaly observed in the mid20th century [43], such anomalies were considered a regional manifestation. Only in the last decade did indirect (model-based) [44] and reconstructed data begin to appear, suggesting that there was a significant (comparable to present) negative anomaly of Arctic sea-ice area during the ETCW [45]. Full gridded datasets have been developed which are based on the analysis of regional data [46], as well as on the relationships between ice-cover and temperature anomalies [37, 47]. Examples of such reconstructions are given in Fig. 2b, showing that ETCW was accompanied by a large negative sea-ice area anomaly, which, however, was about half of the present one. A thorough analysis of station data made it possible to extend back (to the early 20th century) knowledge of Arctic cloudiness [48], perhaps the least studied climate characteristic, which 
is the key to energy balance and one of major sources of uncertainties in climate models. Among reconstructions, paleoreconstructions of Arctic sea-ice area over the past 1450 years [3] and of the intensity of warm Atlantic water inflow to the Arctic in the past 2000 years [49] are noteworthy, both suggestive of the unprecedented current changes.

Considerable progress has been made in the development of climate models and in their ability to reproduce Arctic climate change. The spatial resolution of models has significantly increased over the past decade; in particular, the Coupled Model Intercomparison Project Version 5 (CMIP5) model ensemble generally better reproduces Arctic sea-ice characteristics than the previous-generation CMIP3 models [50]. Regional Arctic climate models, including coupled atmosphere-ocean-ice models, have been developed, providing a comprehensive study of climatechange processes. Such models reproduce regional features of Arctic climate variability, particularly cyclone activity (including mesocyclones), much better than lower resolution global models, while a model ensemble provides assessments of the robustness of the results [51, 52].

\section{NEW PROCESSES}

Progress in oceanographic measurements, simulation, and theoretical research of Arctic climate in the early 20th century has resulted in the discovery of new processes and feedbacks in the Arctic climate system. There are many noteworthy findings in this field, only some of which can be mentioned here.

One recently revealed important process is the Atlantification of near-Atlantic regions of the Arctic Ocean (AO), mainly in the Barents Sea and in the Eurasian Basin [53, 54]. This process qualitatively changes the vertical ocean structure along the pathways where warm Atlantic water enters the Arctic [55, 56]. The seaice decline in the Barents Sea with an increase in the temperature and salinity of inflowing Atlantic water reduces vertical stratification and intensifies the heat exchange between the Atlantic water at depths greater than $100 \mathrm{~m}$ under the surface and the surface layer. This further prevents ice formation and leads to the formation of a deepened homogeneous mixed layer and to a weakening of the pycnocline, which resembles winter stratification in the North Atlantic (hence, Atlantification). It is important that such a process involves a positive feedback and the new state may become stable and irreversible [56, 57].

Another process facilitating the rapid melt of multiyear sea ice is also associated with Atlantic water inflow to the AO. This branch of Atlantic inflow from the Fram Straight goes between Spitsbergen and Josef Franz Land in the Nansen Basin. The analysis of buoy measurements of the vertical ocean structure in the early 21 st century and numerical modeling of convec- tion processes have revealed a positive feedback between the reduced ice thickness and area and thermohaline circulation mixing the warm Atlantic water with a surface layer, which further intensifies ice melt $[56,57]$.

A new positive feedback was found between the Atlantic water inflow to the Barents Sea and sea-ice thickness, operating through the increased watervapor content in the atmosphere in winter due to the reduced sea-ice area. Owing to the specific response of atmospheric circulation to ice-area decline, the positive water-vapor anomaly extends to the central AO, leading to an increase in the downward longwave radiation and to additional ice thinning [58].

The accumulation of oceanographic data in the Atlantic sector of the Arctic, including direct measurements of oceanic heat inflow to the Barents Sea since the early 21 st century (see above), has allowed a detailed investigation into the atmosphere-ocean interaction processes in the Barents Sea, a region of maximum climate variability in the Arctic $[59,60]$. It was shown that the oceanic inflow to the Barents Sea in summer explains over $80 \%$ of the variance of sea-ice area in the entire Arctic the following winter [61] and can serve a sufficiently reliable predictor of winter seaice area anomalies up to 2 years in advance [62]. Moreover, data on the state of the ocean in the northern regions of the North Atlantic and of the seas in the Atlantic sector of the Arctic can allow a prediction of climate anomalies in northern Europe up to 10 years in advance [63].

An important step to understanding mechanisms inducing climate changes in the Arctic was the elucidation of a significant role of internal natural fluctuations of the ocean-atmosphere system in the North Pacific, called the Pacific Decadal Oscillation (PDO). While the impact of AMO on the long-term climate fluctuations in the NH and in the Arctic has been suggested by some studies already as 15-20 years ago [64-67], the contribution of the Pacific Ocean processes to current climate changes began being talked about in the context of the so-called hiatus of global warming in the first decade of the 21st century [68]. In recent years, papers have been published which suggest that the PDO plays a comparable (to the AMO) and, possibly, leading role in the warming of the mid-20th century and in the current amplification of global warming in the Arctic [69-72]. The mechanism of this forcing is associated mainly with a change in the intensity of the Aleutian low and with anomalous heat advection to the Arctic. The hypothesis that temperature anomalies in the tropical Atlantic influence climate fluctuations in the Arctic should also be mentioned [73].

The maximum of climate variability in the Atlantic sector of the Arctic, mainly in the Barents Sea, is explained by variations in the warm Atlantic water inflow and by their close connection with sea-ice area and turbulent heat fluxes from the ocean to the atmo- 


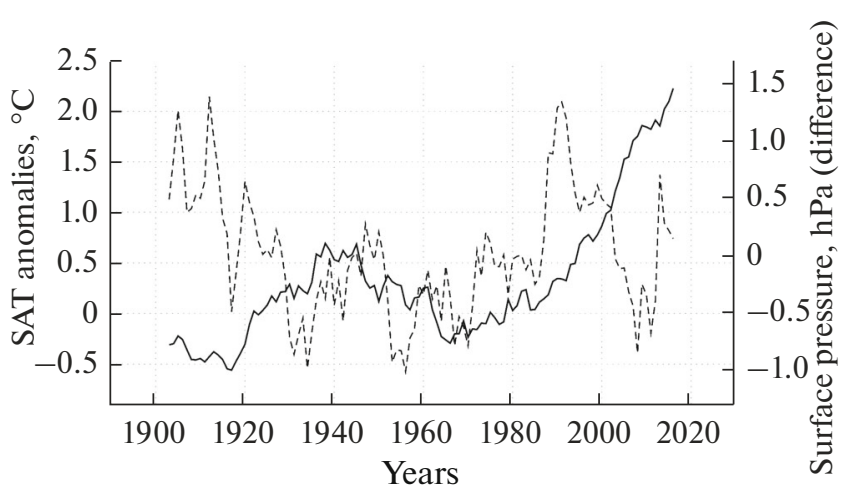

Fig. 3. NAO index as the anomaly of surface-pressure difference between Lisbon and Reykjavik (hPa; dashed curve; the axis on the right)) and annual mean temperature anomaly in the Arctic ( ${ }^{\circ} \mathrm{C}$, solid curve; the axis on the left). Time series are smoothed with a 5-year running mean.

sphere in the relatively shallow Barents Sea. Mechanisms for positive feedbacks able to enhance variations in the oceanic inflow to the Barents Sea were proposed in the early 20th century [19]. One such feedback forms due to a cyclonic response of atmospheric circulation over the Barents Sea to sea-ice decline induced by a positive anomaly of oceanic inflow. This strengthens southwesterly winds, increases the positive south-north ocean level gradient, and further enhances inflow [74, 75]. It was shown that such a positive feedback amplifying the negative inflow anomaly may lead to the shutdown of oceanic inflow and abrupt regional climate changes [76], suggesting tipping points in the Arctic climate system, a concept explaining abrupt regional climate changes [77]. As the sea-ice area in the Barents Sea decreases, the sea loses more heat and denser cold water forms in the eastern part of the sea, increasing the outflow from the Barents Sea and lowering the sea level in the east, intensifying the inflow on the western border of the sea [19]. This process forms one more positive feedback. Another positive feedback is also noteworthy whereby southerly winds increase on the continental border of the sea caused by larger open water area, further decrease the sea-ice area due to atmospheric heat advection and dynamic forcing [78].

Several anomalously cold winters in the early 21st century in northern Eurasia, including Europe, despite record high global temperature, once again made the response of $\mathrm{NH}$ mid- and high-latitude atmospheric circulation to the sea-ice decline and AA a challenging problem, which has been extensively discussed since the 1970s with the development of numerical atmospheric modeling (starting in [79, 80]). In [81, 82], it was shown that strong negative wintertime temperature anomalies in the early 21st century may have been driven by the accelerated sea-ice decline in the eastern Arctic. Afterward, this issue has been extensively studied (e.g., [4, 5, 83, 84]), often with controversial results, which will be dis- cussed in the section devoted to the remaining unanswered questions in Arctic climate research.

It was noted that changes in characteristics of $\mathrm{NH}$ midlatitude weather regimes with accelerated Arctic warming, as well as the atmospheric response to Arctic sea-ice decline, can be essentially nonlinear, thus making it impossible to extrapolate the tendencies observed in the present period to the future $[82,85,86]$.

Elucidating the important role of high-latitude troposphere/stratosphere coupling was significant progress in investigating mechanisms for Arctic climate anomalies. In particular, planetary-wave generation changes driven by anomalous heating in the NH high latitudes can impact the polar vortex. The signal, with some delay, propagates back to the troposphere, affecting the NAO and weather regimes (e.g., [4]). Model experiments have suggested an essential role of troposphere/stratosphere coupling in NAO-AMO connections [87] and in generating atmospheric response to ice-cover anomalies [88].

\section{CHANGE OF CONCEPTS}

Some concepts of Arctic climate change in the last decades of the 20th century have fundamentally changed in the early 21 st century. It has already been noted above that the role of positive surface albedotemperature feedback has been recognized as not the major one in accelerated Arctic climate change. Radiative and dynamic feedbacks described in the previous sections appear to be other major contributors to AA.

In the context of the varying concepts, it seems important to consider a hypothesis on the role of the NAO in accelerated Arctic warming in the last three decades of the 20th century. Because the NAO index and Arctic temperature were rising simultaneously in that period (Fig. 3), it was hypothesized that the enhancement of warm advection to polar latitudes in transition to a positive NAO phase (and, in general, pressure decrease over the central Arctic) increases the positive temperature trend in the Arctic [89]. The positive NAO trend from the mid-1960s was attributed to the external forcing. It was assumed that this is related to the radiative cooling of the stratosphere and lower troposphere with increase in carbon dioxide concentrations and to a weakening of the polar vortex [90]. It was also assumed, on the basis of results from model experiments, that the positive NAO trend is a response to a characteristic pattern (tripole) of sea-surface temperature (SST) anomalies in the North Atlantic [91] or in the tropical Indian and Pacific oceans [92].

An analysis of the ocean-atmosphere interaction with a conceptual stochastic model has shown that results of the abovementioned model experiments can be misinterpreted and are not evidence of SST forcing of the NAO [93]. Further, prolonged climate model experiments and statistical analysis of the distribution function of the NAO trends have shown that a hypoth- 
esis that the observed 30-year positive NAO trends are stochastic cannot be rejected using available relatively short observational time series. It was also demonstrated that the previously derived connection between SST and NAO patterns from the mid-1990s was no longer consistent with the observed dynamics of the NAO index [94]. At present, in 2020, it is already evident that a 30 -year positive trend in the late 20th century is changed by the 20 -year negative trend of comparable amplitude going alone with a stronger increase in greenhouse-gas concentration. Thus, the hypothesis that the NAO increase was solely forced by the global warming proved to be inconsistent, and the negative trend is explained, among other things, by a weakening of the polar vortex because of the increased flux of wave activity to the stratosphere.

Another concept revised in the early 21 st century also concerns the NAO, suggesting that the NAO plays a dominant role in decadal climate fluctuations in the Arctic. This, in particular, was evidenced by high correlation of the NAO with oceanographic characteristics in the Atlantic sector of the Arctic [95]. However, it turned out that the link of the NAO to Arctic climate was nonstationary, and the correlation between the NAO and Arctic climate characteristics in the 20 th century varied not only quantitatively, but also qualitatively $[19,66]$.

\section{PROBLEMS TO SOLVE AND URGENT TASKS}

To conclude, some important unresolved problems in understanding current and past Arctic climate changes and predicting future ones should be mentioned. Progress in accumulating empirical data primarily of the state of the Arctic Ocean and the cryosphere has been noted at the beginning of the paper. At the same time, the amount of data on the state of the Arctic climate system is still insufficient to obtain reliable empirical estimates of changes occurring today. The Argo program, deploying a global array of drifting floats, has been operational since 2000 (https://argo.ucsd.edu/); it provides measurements of temperature, salinity, and current velocity to a depth of $2000 \mathrm{~m}$ with nearly full coverage of the oceans, but does not cover the Arctic Ocean. A program for the deployment of Ice-Tethered Profilers (https://www.whoi.edu/page.do?pid=20756), an analogue of Argo for the Arctic, is being developed. The number of weather stations in the Arctic zone has reduced since the early 1990s [8]. Atmospheric reanalyses in the NH high latitudes, due to the lack of direct measurements and problems with satellite data homogeneity, do not always provide reliable information [38], which may lead to a large spread in estimates of climate changes, in particular, of the causes of the AA of global warming [96]. Recent 20th-century reanalyses also do not address the problem with sparse observational data, especially in the first half of the 20th century, which is illustrated in Fig. 4, where annual mean air

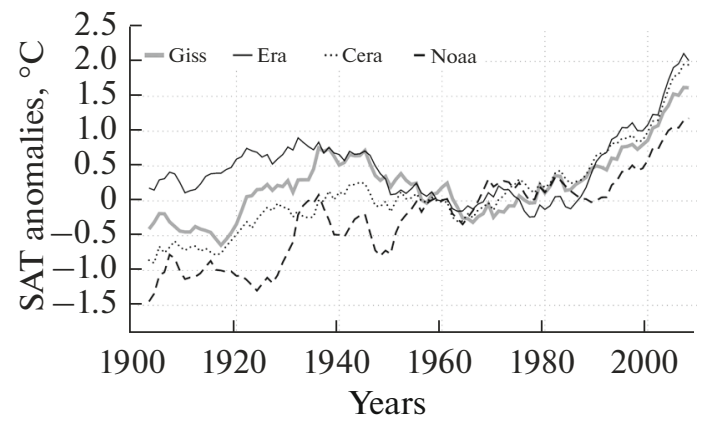

Fig. 4. Annual mean surface temperature anomalies $\left({ }^{\circ} \mathrm{C}\right.$, 5 -year running mean) at Northern Hemisphere high latitudes $\left(60^{\circ}-90^{\circ} \mathrm{N}\right)$ from GISTEMP and 20th-century reanalyses ERA20C, CERA20C, and NOAA20C.

temperature anomalies over land north of $60^{\circ} \mathrm{N}$ from station data and from several 20th-century reanalyses are shown.

Despite the fact that important radiative and dynamic processes driving AA have been revealed, debates about its causes, starting in 2006 [97], continue until now. In particular, there is a significant contribution to AA from water vapor and cloud processes [98]. Apart from the lack of reliable quantitative estimates of the contribution of different factors to the current AA, there is a hypothesis that it is Arctic processes that may be a cause of the accelerated late-20th-century warming in the $\mathrm{NH}$ as a whole, instead of being an amplified manifestation of global warming [17].

There is no consensus either on the relative role of external radiative forcing, mainly human-induced increases in atmospheric greenhouse-gas concentrations, or of internal Arctic climate variability in the current trends. On the one hand, observations show steady quasi-cyclic climate fluctuations in northern polar latitudes $[43,99,100,101]$, implying a significant contribution of natural climate fluctuations to current warming. On the other hand, some climate models almost ideally reproduce Arctic temperature changes in the modern period as a response to external radiative forcing $[102,103]$. The reduction in sea-ice area in the models on the whole is increasingly more consistent with observations [1]. Such results suggest a dominant role of external factors and leave no room for natural climate variability in the current warming. This issue is of fundamental importance because, with such natural fluctuations, Arctic warming must give way to may be replaced by cooling or significantly slow down in the near decade. It should be remembered, however, that the present state of climate is much different from the preindustrial one; positive feedbacks, tipping points, and new processes such as "Atlantification" indicate that the Arctic climate system may shift to a new dynamic regime with no large quasicyclic fluctuations.

The key point in understanding the role that natural climate variability plays in current warming and in 
sea-ice decline in the Arctic is the mid-20th century warming, whose mechanisms are also still being discussed [17, 72].

Large uncertainties remain in the atmospheric circulation response to AA and to reduced Arctic ice area (e.g., [84]). Numerous studies suggest that AA results in more frequent atmospheric circulation patterns driving extreme weather events (e.g., [104, 105]), but this point of view is being arguably disputed (e.g., $[106,107])$. On the other hand, a decrease in the meridional temperature gradient in the NH mid- and high latitudes due to accelerated warming of the Arctic weakens cold (and warm) intrusions and, hence, the variability of temperature anomalies in general [108]. This is supported by the analysis of daily temperature variations in different spectral ranges using data from Russian stations [109]. It is still an open question of whether the mid-and high-latitude weather becomes more extreme with global warming.

One important problem for a realistic simulation of Arctic atmospheric processes is the parameterization of turbulent heat fluxes at the ocean-ice-atmosphere interface. Some studies show that it is imperfection of parameterizations used in specific Arctic conditions that leads to fundamental errors in reproducing heat fluxes at the lower boundary of the atmosphere (e.g., $[19,110])$. Improving parameterizations of turbulent fluxes and cloud cover in the Arctic is one of the challenging problems urging a solution to improve atmospheric and climate model results.

\section{ACKNOWLEDGMENTS}

I am grateful T.A. Matveeva and D.D. Bokuchava for their help in preparing the figures and Yu.A. Zyulyaeva and an anonymous reviewer for valuable comments.

\section{FUNDING}

This study was supported by the Russian Foundation for Basic Research (project nos. 18-05-60216 and 20-55-71003) and the Russian Science Foundation (project no. 18-4706203) in analysis of extreme weather events.

\section{OPEN ACCESS}

This article is distributed under the terms of the Creative Commons Attribution 4.0 International Public License (http://creativecommons.org/licenses/by/4.0/), which permits unrestricted use, distribution, and reproduction in any medium provided you give appropriate credit to the original author(s) and the source, provide a link to the Creative Commons license, and indicate if changes were made.

\section{REFERENCES}

1. V. A. Semenov, T. Martin, L. K. Behrens, and M. Latif, "Arctic sea ice area in CMIP3 and CMIP5 climate model ensembles-variability and change," Cryosphere Discuss. 9, 1077-1131 (2015).

2. J. Overpeck, K. Hughen, D. Hardy, R. Bradley, R. Case, M. Douglas, B. Finney, K. Gajewski, G. Jacoby, A. Jennings, S. Lamoureux, A. Lasca, G. MacDonald, J. Moore, M. Retelle, S. Smith, A. Wolfe, and G. Zielinski, "Arctic environmental change of the last four centuries," Science 278 (5341), 1251-1256 (1997).

3. C. Kinnard, C. M. Zdanowicz, D. A. Fisher, E. Isaksson, A. de Vernal, and L. G. Thompson, "Reconstructed changes in Arctic sea ice over the past 1450 years," Nature 479, 509-512 (2011).

4. J. Cohen, J. A. Screen, J. C. Furtado, M. Barlow, D. Whittleston, D. Coumou, J. Francis, K. Dethloff, D. Entekhabi, J. Overland, and J. Jones, "Recent Arctic amplification and extreme mid-latitude weather," Nat. Geosci. 7, 627-637 (2014).

5. I. I. Mokhov and V. A. Semenov, "Weather and climate anomalies in Russian regions related to global climate change," Russ. Meteorol. Hydrol. 41 (2), 84-92 (2016).

6. Arctic Climate Impact Assessment. ACIA Overview Report (Cambridge University Press, Cambridge, 2005).

7. The Second Assessment Report of Russian Hydrometeorological Service on Climate Changes and Their Consequences on the Territory of the Russian Federation (Rosgidromet, Moscow, 2014) [in Russian].

8. R. V. Bekryaev, I. V. Polyakov, and V. A. Alexeev, "Role of polar amplification in long-term surface air temperature variations and modern Arctic warming," J. Clim. 23, 3888-3906 (2010).

9. M. I. Budyko, "The effect of solar radiation variations on the climate of the Earth," Tellus 21, 611-619 (1969).

10. M. Winton, "Amplified Arctic climate change: What does surface albedo feedback have to do with it?," Geophys. Res. Lett. 33, L03701 (2006).

11. V. A. Alexeev, P. L. Langen, and J. R. Bates, "Polar amplification of surface warming on an aquaplanet in ghost forcing experiments without sea ice feedbacks," Clim. Dyn. 24, 655-666 (2005).

12. F. Pithan and T. Mauritsen, "Arctic amplification dominated by temperature feedbacks in contemporary climate models," Nat. Geosci. 7 (3), 181-184 (2014).

13. N. Lenssen, G. Schmidt, J. Hansen, M. Menne, A. Persin, R. Ruedy, and D. Zyss, "Improvements in the GISTEMP uncertainty model," J. Geophys. Res.: Atmos. 124 (12), 6307-6326 (2019).

14. D. D. Bokuchava and V. A. Semenov, "Analysis of surface air temperature anomalies in the Northern Hemisphere in the 20th century according to observational and reanalysis data," Fundam. Prikl. Klimatol., No. 1, 28-51 (2018).

15. L. H. Smedsrud, I. Esau, R. B. Ingvaldsen, T. Eldevik, P. M. Haugan, C. Li, V. S. Lien, A. Olsen, A. M. Omar, O. H. Otterå, B. Risebrobakken, A. B. Sandø, V. A. Semenov, and S. A. Sorokina, "The role of the Barents Sea in the Arctic climate system," Rev. Geophys. 51 (3), 415-449 (2013).

16. J. Walsh, "The elusive Arctic warming," Nature 361, 300-301 (1993).

17. G. C. Hegerl, S. Brönnimann, A. Schurer, and T. Cowan, "The early 20th century warming: Anomalies, causes, and consequences," Wiley Interdiscip. Rev.: Clim. Change 9 (4), e522 (2018). 
18. M. E. Schlesinger and N. Ramankutty, "An oscillation in the global climate system of period 65-70 years," Nature 367, 723-726 (1994).

19. T. L. Delworth and T. R. Knutson, "Simulation of early $20^{\text {th }}$ century global warming," Science $287,2246-$ 2250 (2000).

20. V. A. Semenov, M. Latif, D. Dommenget, N. S. Keenlyside, A. Strehz, T. Martin, and W. Park, "The impact of North Atlantic-Arctic multidecadal variability on Northern Hemisphere surface air temperature," J. Clim. 23, 5668-5677 (2010).

21. E. van der Swaluw, S. S. Drijfhout, and W. Hazeleger, "Bjerknes compensation at high northern latitudes: The ocean forcing the atmosphere," J. Clim. 20, 6023-6032 (2007).

22. I. V. Polyakov, G. V. Alekseev, R. V. Bekryaev, U. Bhatt, R. L. Colony, M. A. Johnson, V. P. Karklin, A. P. Makshtas, D. Walsh, and V. Yulin, "Observationally based assessment of polar amplification of global warming," Geophys. Res. Lett. 29 (18), 25-1-25-4 (2002).

23. I. I. Mokhov, "Contemporary climate changes in the Arctic," Herald Russ. Acad. Sci. 85 (5-6), 265-271 (2015).

24. I. V. Polyakov, V. A. Alexeev, I. M. Ashik, S. Bacon, A. Beszczynska-Möller, E. C. Carmack, I. A. Dmitrenko, L. Fortier, J. C. Gascard, E. Hansen, Jens. Hölemann, V. V. Ivanov, T. Kikuchi, S. Kirillov, Y. D. Lenn, F. A. McLaughlin, J. Piechura, I. Repina, L. A. Timokhov, W. Walczowski, and R. Woodgate, "Fate of early 2000s Arctic warm water pulse," Bull. Am. Meteorol. Soc. 92 (5), 561-566 (2011).

25. I. V. Polyakov, A. V. Pnyushkov, M. B. Alkire, I. M. Ashik, T. M. Baumann, E. C. Carmack, et al., "Greater role for Atlantic inflows on sea ice loss in the Eurasian basin of the Arctic Ocean," Science 356 (6335), 285291 (2017).

26. R. B. Ingvaldsen, L. Asplin, and H. Loeng, "Velocity field of the western entrance to the Barents Sea," J. Geophys. Res. 109, C03021 (2004).

27. A. Behrendt, H. Sumata, B. Rabe, and U. Schauer, "UDASH-Unified database for Arctic and subarctic hydrography," Earth Syst. Sci. Data 10, 1119-1138 (2018).

28. D. J. Cavalieri, C. L. Parkinson, P. Gloersen, et al., "Deriving long-term time series of sea ice cover from satellite passive-microwave multi-sensor data sets," J. Geophys. Res. 104, 15803-15814 (1999).

29. R. Lindsay and A. Schweiger, "Arctic Sea ice thickness loss determined using subsurface, aircraft, and satellite observations," Cryosphere 9, 269-283 (2015).

30. A. P. Nagurnyi, Climate tendencies of changes in multilayer sea ice thickness in the Arctic basin (1970-205), Russ. Meteorol. Hydrol. 34 (9), 613-617 (2009).

31. O. M. Johannessen, L. Bengtsson, M. W. Miles, S. I. Kuzmina, V. A. Semenov, G. V. Alekseev, A. P. Nagurnyi, V. F. Zakharov, L. Bobylev, L. Pettersson, K. Hasselmann, and H. P. Cattle, "Arctic climate change: Observed and modeled temperature and seaice variability," Tellus 56A, 328-341 (2004).

32. G. Holloway and T. Sau, "Has Arctic Sea ice rapidly thinned?," J. Clim. 15, 1691-1698 (2002).

33. S. W. Laxon, K. A. Giles, A. L. Ridout, D. J. Wingham, R. Willatt, R. Cullen, R. Kwok, A. Schweiger, J. Zhang, C. Haas, S. Hendricks, R. Krishfield,
N. Kurtz, S. Farrell, and M. Davidson, "CryoSat-2 estimates of Arctic sea ice thickness and volume," Geophys. Res. Lett. 40, 732-737 (2013).

34. J. L. Zhang and D. A. Rothrock, "Modeling global sea ice with a thickness and enthalpy distribution model in generalized curvilinear coordinates," Mon. Weather Rev. 131, 845-861 (2003).

35. N. Ferry, E. Remy, P. Brasseur, and C. Maes, "The Mercator global ocean operational analysis forecast system: Assessment and validation of an 11-year reanalysis,” J. Mar. Syst. 65, 540-560 (2007).

36. D. Schroder, D. L. Feltham, M. Tsamados, A. Ridout, and R. Tilling, "New insight from CryoSat-2 sea ice thickness for sea ice modeling," Cryosphere 13, 125139 (2019).

37. V. A. Semenov and T. A. Matveeva, "Arctic Sea ice in the first half of the 20th century: Temperature-based spatiotemporal reconstruction," Izv., Atmos. Ocean. Phys. 56 (5) 534-538 (2020).

38. R. M. Graham, L. Cohen, N. Ritzhaupt, B. Segger, R. G. Graversen, A. Rinke, V. P. Walden, M. A. Granskog, and S. R. Hudson, "Evaluation of six atmospheric reanalyses over Arctic Sea ice from winter to early summer," J. Clim. 32 (14), 4121-4143 (2019).

39. G. P. Compo, J. S. Whitaker, P. D. Sardeshmukh, N. Matsui, R. J. Allan, X. Yin, and S. Brönnimann, "The twentieth century reanalysis project," Q. J. R. Meteorol. Soc. 137 (654), 1-28 (2011).

40. H. Hersbach, C. Peubey, A. Simmons, P. Berrisford, P. Poli, and D. Dee, "ERA-20CM: a twentieth-century atmospheric model ensemble," Q. J. R. Meteorol. Soc. 141 (691), 2350-2375 (2015).

41. P. Laloyaux, M. Balmaseda, D. Dee, K. Mogensen, P. Janssen, "A coupled data assimilation system for climate reanalysis,” Q. J. R. Meteorol. Soc. 142 (694), 65-78 (2016).

42. A. J. Schweiger, K. R. Wood, and J. Zhang, "Arctic Sea ice volume variability over 1901-2010: A modelbased reconstruction," J. Clim. 32, 4731-4752 (2019).

43. G. V. Alekseev, A. I. Danilov, V. M. Kattsov, S. I. Kuz'mina, and N. E. Ivanov, "Changes in the climate and sea ice of the Northern Hemisphere in the 20th and 21st centuries from data of observations and modeling," Izv., Atmos. Ocean. Phys. 45 (6) 675-686 (2009).

44. V. A. Semenov and M. Latif, "The early twentieth century warming and winter Arctic Sea ice," Cryosphere 6, 1231-1237 (2012).

45. G. Alekseev, N. Glok, and A. Smirnov, "On assessment of the relationship between changes of sea ice extent and climate in the Arctic," Int. J. Climatol. 36 (9), 3407-3412 (2016).

46. J. E. Walsh, F. Fetterer, S. J. Stewart, and W. L. Chapman, "A database for depicting Arctic Sea ice variations back to 1850," Geogr. Rev. 107 (1), 89-107 (2017).

47. M. K. Brennan, G. J. Hakim, and E. Blanchard-Wrigglesworth, "Arctic sea-ice variability during the instrumental era," Geophys. Res. Lett. 47, GL086843 (2020).

48. A. V. Chernokulsky, I. Esau, O. N. Bulygina, R. Davy, I. I. Mokhov, S. Outten, and V. A. Semenov, "Climatology and interannual variability of cloudiness in the Atlantic Arctic from surface observations since the late nineteenth century,” J. Clim. 30 (6), 2103-2120 (2017).

49. R. F. Spielhagen, K. Werner, S. A. Sorensen, K. Zamelczyk, E. Kandiano, G. Budeus, K. Husum, 
T. M. Marchitto, and M. Hald, "Enhanced modern heat transfer to the Arctic by warm Atlantic water," Science 331 (6016), 450-453 (2011).

50. V. A. Semenov, T. Martin, L. K. Behrens, M. Latif, and E. S. Astaf'eva, "Arctic sea-ice area changes in ensembles of CMIP3 and CMIP5 climate models," Led Sneg 57 (1), 77-107 (2017).

51. M. Akperov, A. Rinke, I. I. Mokhov, H. Matthes, V. A. Semenov, M. Adakudlu, J. Cassano, J. H. Christensen, M. A. Dembitskaya, K. Dethloff, X. Fettweis, J. Glisan, O. Gutjahr, G. Heinemann, T. Koenigk, N. V. Koldunov, R. Laprise, R. Mottram, O. Nikiema, J. F. Scinocca, D. Sein, S. Sobolowski, K. Winger, and W. Zhang, "Cyclone activity in the Arctic from an ensemble of regional climate models (Arctic CORDEX)," J. Geophys. Res.: Atmos. 123 (5), 2537-2554 (2018).

52. M. Akperov, V. A. Semenov, I. I. Mokhov, W. Dorn, and A. Rinke, "Impact of Atlantic water inflow on winter cyclone activity in the Barents Sea: Insights from coupled regional climate model simulations," Environ. Res. Lett. 15, 024009 (2020).

53. I. V. Polyakov, A. V. Pnyushkov, R. Rember, L. Padman, E. C. Carmack, and J. M. Jackson, "Winter convection transports Atlantic water heat to the surface layer in the eastern Arctic Ocean," J. Phys. Oceanogr. 43, 2142-2155 (2013).

54. S. Lind, R. B. Ingvaldsen, and T. Furevik, "Arctic warming hotspot in the northern Barents Sea linked to declining sea-ice import," Nat. Clim. Change 8, 634639 (2018).

55. V. V. Ivanov, V. A. Alexeev, I. A. Repina, N. V. Koldunov, and A. V. Smirnov, "Tracing Atlantic water signature in the Arctic sea ice cover east of Svalbard," Adv. Meteorol. 2012, 201818 (2012).

56. V. V. Ivanov, V. A. Alexeev, N. V. Koldunov, I. A. Repina, A. B. Sando, L. H. Smedsrud, and A. V. Smirnov, "Arctic Ocean heat impact on regional ice decay: A suggested positive feedback," J. Phys. Oceanogr. 46 (5), 1437-1456 (2016).

57. V. Ivanov, A. Smirnov, V. Alexeev, N. V. Koldunov, I. Repina, and V. Semenov, "Contribution of convection-induced heat flux to winter ice decay in the western Nansen Basin," J. Geophys. Res.: Oceans 123, 6581-6597 (2018).

58. V. A. Alexeev, J. E. Walsh, V. V. Ivanov, V. A. Semenov, and A. V. Smirnov, "Warming in the Nordic seas, North Atlantic storms and thinning Arctic sea ice," Environ. Res. Lett. 12, 084011 (2017).

59. P. Schlichtholz, "Observational evidence for oceanic forcing of atmospheric variability in the Nordic seas area,” J. Clim. 26, 2957-2975 (2013).

60. P. Schlichtholz, "Local wintertime tropospheric response to oceanic heat anomalies in the Nordic seas area," J. Clim. 27, 8686-87 (2014).

61. P. Schlichtholz, "Subsurface ocean flywheel of coupled climate variability in the Barents Sea hotspot of global warming," Sci. Rep. 9, 13692 (2019).

62. I. H. Onarheim, T. Eldevik, M. Årthun, B. R. Ingvaldsen, and L. H. Smedsrud, "Skillful prediction of Barents Sea ice cover," Geophys. Res. Lett. 42, 53645371 (2015).

63. M. Årthun, T. Eldevik, E. Viste, H. Drange, T. Furevik, H. L. Johnson, and N. S. Keenlyside, "Skillful prediction of northern climate provided by the ocean," Nat. Commun. 8, 15875 (2017).
64. T. L. Dellworth, S. Manabe, and R. J. Stouffer, "Interdecadal variations of the thermohaline circulation in a coupled ocean-atmosphere model," J. Clim. 6, 19932011 (1993).

65. I. V. Polyakov, G. V. Alekseev, L. A. Timokhov, U. S. Bhatt, R. L. Colony, H. L. Simmons, D. Walsh, J. E. Walsh, and V. F. Zakharov, "Variability of the intermediate Atlantic water of the Arctic Ocean over the last 100 years," J. Clim. 17, 4485-4497 (2004).

66. V. A. Semenov, "Influence of oceanic inflow to the Barents Sea on climate variability in the Arctic region," Dokl. Earth Sci. 418 (1), 91-94 (2008).

67. S. Levitus, G. Matishov, D. Seidov, and I. Smolyar, "Barents Sea multidecadal variability," Geophys. Res. Lett. 36 (19), L19604 (2009).

68. Y. Kosaka and S. Xie, "Recent global-warming hiatus tied to equatorial Pacific surface cooling," Nature 501, 403-407 (2013).

69. H. Tokinaga, S. P. Xie, and H. Mukougawa, "Early $20^{\text {th }}$-century Arctic warming intensified by Pacific and Atlantic multidecadal variability," Proc. Natl. Acad. Sci. 114 (24), 6227-6232 (2017).

70. M. Wegmann, S. Brönnimann, and G. P. Compo, "Tropospheric circulation during the early twentieth century Arctic warming," Clim. Dyn. 48 (7-8), 24052418 (2017).

71. L. Svendsen, N. Keenlyside, I. Bethke, Y. Gao, and N. E. Omrani, "Pacific contribution to the early twentieth-century warming in the Arctic," Nat. Clim. Change 8, 793-797 (2018).

72. V. N. Malinin and P. A. Vainovskii, "On the causes of the first Arctic warming in the 20th century," Uch. Zap. Ross. Gos. Gidrometeorol. Univ. 53, 34-55 (2018).

73. G. V. Alekseev, S. I. Kuzmina, N. I. Glok, A. E. Vyazilova, N. E. Ivanov, and A. V. Smirnov, "Influence of the Atlantic on the warming and reduction of sea ice in the Arctic," Led Sneg 57 (3), 381-390 (2017).

74. L. Bengtsson, V. A. Semenov, and O. M. Johannessen, "The early twentieth-century century warming in the Arctic-a possible mechanism," J. Clim. 17, 40454057 (2004).

75. K. A. Kalavichchi and I. L. Bashmachnikov, "Mechanism of a positive feedback in long-term variations of the convergence of oceanic and atmospheric heat fluxes and of the ice cover in the Barents Sea," Izv., Atmos. Ocean. Phys. 55 (6), 640-649 (2019).

76. V. A. Semenov, W. Park, and M. Latif, "Barents Sea inflow shutdown: A new mechanism for rapid climate changes," Geophys. Res. Lett. 36, L14709 (2009).

77. T. M. Lenton, "Arctic climate tipping points," Ambio 41 (1), 10-22 (2012).

78. A. N. Zolotokrylin, A. Yu. Mikhailov, and T. B. Titkova, "Effect of warm Atlantic waters on the climate anomalies in the west Arctic," Led Sneg 55 (3), 73-82 (2015).

79. R. L. Newson, "Response of a general circulation model of the atmosphere to removal of the Arctic icecap," Nature 241, 39-40 (1973).

80. G. T. Herman and W. T. Johnson, "The sensitivity of the general circulation of Arctic Sea ice boundaries: A numerical experiment," Mon. Weather Rev. 106, 1649-1664 (1978). 
81. M. Honda, J. Inoue, and S. Yamane, "Influence of low Arctic sea-ice minima on wintertime Eurasian coldness,” Geophys. Res. Lett. 36, L08707 (2009).

82. V. Petoukhov and V. A. Semenov, "A link between reduced Barents-Kara sea ice and cold winter extremes over northern continents," J. Geophys. Res.: Atmos. 115, D21111 (2010).

83. T. Vihma, "Effects of Arctic sea ice decline on weather and climate: A review," Surv. Geophys. 35, 1175-214 (2014).

84. V. P. Meleshko, V. M. Kattsov, V. M. Mirvis, A. V. Baidin, T. V. Pavlova, and V. A. Govorkova, "Is there a link between Arctic sea ice loss and increasing frequency of extremely cold winters in Eurasia and North America? Synthesis of current research," Russ. Meteorol. Hydrol. 43 (11), 743-755 (2018).

85 . V. A. Semenov and M. Latif, "Nonlinear winter atmospheric circulation response to Arctic sea ice concentration anomalies for different periods during 19662012,” Environ. Res. Lett. 10, 054020 (2015).

86. J. E. Overland, K. Dethloff, J. A. Francis, R. J. Hall, E. Hanna, S. J. Kim, J. A. Screen, T. G. Shepherd, and T. Vihma, "Nonlinear response of mid-latitude weather to the changing Arctic," Nat. Clim. Change 6 (11), 992 (2016).

87. N. Omrani, N. S. Keenlyside, J. Bader, and E. Manzini, "Stratosphere key for wintertime atmospheric response to warm Atlantic decadal conditions," Clim. Dyn. 42, 649-663 (2014).

88. B. M. Kim, S. W. Son, S. K. Min, J. H. Jeong, S. J. Kim, X. Zhang, T. Shim, and J. H. Yoon, "Weakening of the stratospheric polar vortex by Arctic sea-ice loss," Nat. Commun. 5, 4646 (2014).

89. R. E. Moritz, C. M. Bitz, and E. J. Steig, "Dynamics of recent climate change in the Arctic," Science 297, 1497-1502 (2002).

90. D. T. Shindell, R. L. Miller, G. A. Schmidt, and L. Pandolfo, "Simulation of recent northern winter climate trends by greenhouse-gas forcing," Nature 399, 452-455 (1999).

91. M. J. Rodwell, D. P. Rowell, and C. K. Folland, "Oceanic forcing of the wintertime North Atlantic Oscillation and European climate," Nature 398, 320-323 (1999).

92. M. P. Hoerling, J. W. Hurrell, and T. Xu, "Tropical origins for recent North Atlantic climate change," Science 292, 90-92 (2001).

93. C. S. Bretherton and D. S. Battisti, "An interpretation of the results from atmospheric general circulation models forced by the time history of the observed sea surface temperature distribution," Geophys. Res. Lett. 27, 767-770 (2000).

94. V. A. Semenov, M. Latif, J. H. Jungclaus, and W. Park, "Is the observed NAO variability during the instrumental record unusual?," Geophys. Res. Lett. 35, L11701 (2008).

95. R. R. Dickson, T. J. Osborn, J. W. Hurrell, J. Meincke, J. Blindheim, B. Adlandsvik, T. Vinje, G. Alekseev, and W. Maslowski, "The Arctic Ocean response to the North Atlantic Oscillation," J. Clim. 13, 2671-2696 (2000).
96. V. A. Alexeev, I. Esau, I. V. Polyakov, S. J. Byam, and S. Sorokina, "Vertical structure of recent Arctic warming from observed data and reanalysis products," Clim. Change 111, 215-239 (2012).

97. M. C. Serreze and J. A. Francis, "The Arctic amplification debate," Clim. Change 76, 241-264 (2006).

98. M. Yoshimori, M. Watanabe, A. Abe-Ouchi, H. Shiogama, and T. Ogura, "Relative contribution of feedback processes to Arctic amplification of temperature change in MIROC GCM," Clim. Dyn. 42, 1613-1630 (2014).

99. I. E. Frolov, Z. M. Gudkovich, V. P. Karklin, E. G. Kovalev, and V. M. Smolyanitskii, Scientific Research in the Arctic, vol. 2: Climate Changes in the Ice Cover of Eurasian Shelf Seas (Nauka, St. Petersburg, 2007) [in Russian].

100. A. R. Mahoney, R. G. Barry, V. Smolyanitsky, and F. Fetterer, "Observed sea ice extent in the Russian Arctic, 1933-2006," J. Geophys. Res. 113, C11005 (2008).

101. M. W. Miles, D. V. Divine, T. Furevik, E. Jansen, M. Moros, and A. E. J. Ogilvie, "A signal of persistent Atlantic multidecadal variability in Arctic sea ice," Geophys. Res. Lett. 41, 463-469 (2014).

102. N. P. Gillett, D. A. Stone, P. A. Stott, T. Nozawa, A. Y. Karpechko, G. C. Hegerl, M. F. Wehner, and P. D. Jones, "Attribution of polar warming to human influence," Nat. Geosci. 1 (11), 750-754 (2008).

103. J. C. Fyfe, K. von Salzen, N. P. Gillett, V. K. Arora, G. M. Flato, and J. R. McConnell, "One hundred years of Arctic surface temperature variation due to anthropogenic influence," Sci. Rep. 3, 2645 (2013).

104. J. A. Francis and S. J. Vavrus, "Evidence linking Arctic amplification to extreme weather in mid-latitudes," Geophys. Res. Lett. 39, L06801 (2012).

105. B. Crasemann, D. Handorf, R. Jaiser, K. Dethloff, T. Nakamura, J. Ukita, and K. Yamazaki, "Can preferred atmospheric circulation patterns over the North-Atlantic-Eurasian region be associated with Arctic sea ice loss?," Polar Sci. 14, 9-20 (2017).

106. V. P. Meleshko, O. M. Johannessen, A. V. Baidin, T. V. Pavlova, and V. A. Govorkova, "Arctic amplification: Does it impact the polar jet stream?," Tellus A: Dyn. Meteorol. Oceanogr. 68 (1), 32330 (2016).

107. J. Perlwitz, M. Hoerling, and R. Dole, "Arctic tropospheric warming: Causes and linkages to lower latitudes," J. Clim. 28 (6), 2154-2167 (2015).

108. J. A. Screen, "Arctic amplification decreases temperature variance in northern mid-to high-latitudes," Nat. Clim. Change 4 (7), 577 (2014).

109. E. D. Babina and V. A. Semenov, "Intramonthly variability of daily surface air temperature in Russia in 1970-2015,” Russ. Meteorol. Hydrol. 44 (8), 513-522 (2019).

110. A. H. Chaudhuri, R. M. Ponte, and A. T. Nguyen, "A comparison of atmospheric reanalysis products for the Arctic Ocean and implications for uncertainties in air-sea fluxes," J. Clim. 27 (14), 5411-5421 (2014).

Translated by N. Tret'yakova 